\section{Canadian faculties of medicine not in denial}

In their Sept. 7, 2010 editorial, Hébert and colleagues touch on a critical subject: the complicated relationship between industry and medical education. ${ }^{1}$ The authors rightly point out that in many medical schools, "future generations of students are [being] taught by some expert faculty who receive funds from the pharmaceutical industry." They go on to say that "it is time for medical faculties and academic physicians to stop burying their heads in the sand."

Far from burying their hands in the sand, the Board of Directors of the Association of Faculties of Medicine of Canada (AFMC), which comprises all 17 deans of medicine and 4 public members, voted to endorse the principles contained in the Association of American Medical Colleges report on industry funding of medical education that the authors reference. ${ }^{2}$ There can be no clearer signal that the senior leadership of our faculties of medicine is taking action. All of our faculties have reviewed their codes and guidelines relating to conflict of interest and many have made, or are making, substantial advances.

Three important issues must be acknowledged. First, despite the fact that the authors focus exclusively on the pharmaceutical industry, concerns about conflict of interest apply to medical device companies, biotech firms and many other private-sector industries.

Second, AFMC agrees that "medical students deserve a bias-free education." But bias and conflict of interest are not the same thing. Conflicts of interest do not inherently lead to bias, and bias can certainly exist without conflicts of interest.

Third, guidelines, policies and procedural frameworks must be developed in all settings and contexts in which medical students and faculty function. Conflicts of interest must be addressed collectively by our faculties, affiliated hospitals and research institutes, practice settings, home universities, associations such as the CMA, specialty societies and industry.

\section{Nick Busing MD}

President \& CEO, Association of Faculties of Medicine of Canada, Ottawa, Ont.

\section{References}

1. Hébert PC, MacDonald N, Flegel K, et al. Competing interests and undergraduate medical education: time for transparency. CMAJ 2010;182:1279.

2. Industry funding of medical education: report of an AAMC task force. Washington (DC): Association of American Medical Colleges; 2008. Available: http://services.aamc.org/publications/showfile.cfm ?file=version114.pdf\&prd_id=232 $($ accessed 2011 Feb. 9).

CMAJ 2011. DOI:10.1503/cmaj.111-2020

\section{Five steps for ruling out coronary artery disease in general practice}

Brook's idea for creating an acronym ${ }^{1}$ for Bösner and colleagues' prediction rule $^{2}$ is commendable. It would certainly facilitate the use of the score in daily clinical practice. But perhaps the acronym would be easier to remember if it was associated with the cardiovascular system - something like the PEVAsC score:

P: pain not reproducible by palpation

E: exercise-related pain

$\mathrm{V}$ : known vascular disease

As: age/sex $($ men $>55$, women $>65)$

$\mathrm{C}$ : patient assumes pain is of cardiac origin

Careful assessment of clinical probability (estimation of the prediction score) together with other diagnostic tools (i.e., resting electrocardiogram) allows one to exclude coronary origin of chest pain with a much greater confidence than either history and physical examination or electrocardiogram alone. When differentiating chest pain in general practice, it is important that primary care physicians consider serious diseases such as acute coronary syndromes, pulmonary embolism and pneumonia, in addition to more common (but not life-threatening) conditions such as pain in the chest wall, gastroesophageal reflux disease and panic disorder. ${ }^{3}$ Existing prediction scores are valuable complementary measures that may help clarify many of these diagnoses. ${ }^{1,46}$

\section{Bartosz Hudzik MD}

Janusz Szkodzinski MD PhD

Lech Polonski MD PhD

3rd Department of Cardiology, Silesian

Center for Heart Disease, Silesian Medical

University, Zabrze, Poland

\section{References}

1. Brook DR. Primary-care assessment of chest. Available: www.cmaj.ca/cgi/letters/182/12/1295 \#596300.

2. Bösner S, Haasenritter J, Becker A, et al. Ruling out coronary artery disease in primary care: development and validation of a simple prediction rule. CMAJ 2010;182:1295-300.

3. Cayley WE Jr. Diagnosing the cause of chest pain. Am Fam Physician 2005;72:2012-21.

4. Diehr P, Wood RW, Bushyhead J, et al. Prediction of pneumonia in outpatients with acute cough - a statistical approach. J Chronic Dis 1984;37:215-25.

5. Rouan GW, Lee TH, Cook EF, et al. Clinical characteristics and outcome of acute myocardial infarction in patients with initially normal or nonspecific electrocardiograms (a report from the Multicenter Chest Pain Study). Am J Cardiol 1989;64:1087-92.

6. Wells PS, Anderson DR, Rodger M, et al. Derivation of a simple clinical model to categorize patients probability of pulmonary embolism: increasing the models utility with the SimpliRED D-dimer. Thromb Haemost 2000;83: 416-20.

CMAJ 2011. DOI:10.1503/cmaj.111-2021

\section{Better by a marathon's distance than shoes}

There is no question that barefoot running will go a long way toward preventing injuries. ${ }^{1}$ Having come across a suggestion in a book on marathon running to add to one's training repertoire an occasional barefoot run on grass or similar soft ground, I gave it a try.

This was in 1987, and I was what one could call an addict, fitting in two lengthy runs per day, most days. Pushing over $150 \mathrm{~km}$ per week, I was frequently injured, with hamstring tears, Achilles tendon problems and other complaints. So I chose a shorter, 10-km route for my initial barefoot run. 
I acquired blisters on nearly all my toes, but I felt that something wild had been awakened in me. Having bandaged each toe, I repeated the experiment the next day. And I haven't looked back, except with gratitude to the author of that book.

No matter what distances and on what terrain (I do not mind regular bitumen, dirt road or gravel at all), I have not suffered another injury (excluding the occasional piece of glass or a fish hook at the beach), and I am very careful not to venture onto grass because of the real potential of hidden syringes and needles.

More than 20 years later, I will not go back to wearing shoes while running; I am convinced that we are born barefoot for a reason and that any type of shoe isolates the foot from (uneven) ground surfaces while forcing the wearer to land on the heel, which transmits far more force to the joints and connected structures than is prudent.

Forefoot strike is what man is born to use, and anyone can adapt to barefoot running and derive great benefit.

\section{Herbert H. Nehrlich MD}

Bribie Island, Australia

\section{Reference}

1. Collier R. Low-tech running shoes in high demand. CMAJ 2011;183:20

CMAJ 2011. DOI:10.1503/cmaj.111-2022

\section{Inhaler blues?}

Patients frequently refer to inhalers by colour rather than by trade or generic names. ${ }^{1}$ Indeed, many physicians use colour-coded wall charts to help both them and their patients identify inhalers.

Although there is no formal agreement between pharmaceutical companies, both brand and generic drug manufacturers traditionally provide rapidacting $\beta$-agonist bronchodilators (for rescue or reliever therapy) in blue, and inhaled corticosteroid (ICS) inhalers (controller) in shades of orange, brown or red.

One of the major improvements in asthma therapy is the move from symptom relief and overuse of the blue rescue inhalers to regular use of antiinflammatory controller ICS combination inhalers.

However, inconsistency in the colour of inhalers can create a lot of confusion., ${ }^{2,3}$

Guidelines are based on striving for control, and physicians are encouraged to assess control during all patient visits. Physicians commonly determine a patient's use of a rescue bronchodilator by asking, "How often have you used your blue inhaler in the past week?"4 During telephone conversations, physicians or other health care providers, for worsening symptoms, may tell a patient to "increase significantly their blue inhaler."

Why would Health Canada recently approve Zenhale, a new combination inhaler, in the colour blue? Surely this is a risk management issue for patients and physicians and may lead to serious consequences of overdose during exacerbation?

\section{Andrew R. McIvor MD MSc}

Professor of Medicine, McMaster

University, Hamilton, Ont.

\section{References}

1. Hodder R, Lougheed MD, Rowe BH, et al. Management of acute asthma in adults in the emergency department: nonventilatory management. CMAJ 2010;182:55-67.

2. Horn CR, Cochrane GM. Colour coding for bronchodilator inhalers. Lancet 1986;18:1843

3. Partridge M. Coloured inhalers. BMJ 1992;305: 890

4. Balter MS, Bell AD, Kaplan AG, et al. Management of asthma in adults. CMAJ 2009;181:915-22.

CMAJ 2011. DOI:10.1503/cmaj.111-2025

\section{Letters to the editor}

In submitting a letter, you automatically consent to have it appear online and/or in print. All letters accepted for print will be edited by $C M A J$ for space and style. Most references and multiple authors' names and full affiliations will appear online only. (The full version of any letter accepted for print will be posted at cmaj.ca.)
ATIVAN is useful for the short-term relief of manifestations of excessive anxiety in patients with anxiety neurosis. It is also useful as an adjunct for the relief of excessive anxiety that might be present prior to surgical interventions. Anxiety and tension associated with the stresses of everyday life usually do not require treatment with anxiolytic drugs.

ATIVAN is contraindicated in patients with myasthenia gravis or acute narrow angle glaucoma, and in those with known hypersensitivity to benzodiazepines.

Severe anaphylactic/anaphylactoid reactions have been reported with the use of benzodiazepines. Cases of angioedema involving the tongue, glottis or larynx have been reported in patients after taking the first or subsequent doses of benzodiazepines. Some patients taking benzodiazepines have had additional symptoms such as dyspnea, throat closing or nausea and vomiting. Some patients have required medical therapy in the emergency department. If angioedema involves the tongue, glottis or larynx, airway obstruction may occur and be fatal. Patients who develop angioedema after treatment with a benzodiazepine should not be rechallenged with the drug.

ATIVAN is not recommended for use in depressive neurosis or in psychotic reactions. Because of the lack of sufficient clinical experience, lorazepam is not recommended for use in patients less than 18 years of age. Since ATIVAN has a central nervous system depressant effect, patients should be advised against the simultaneous use of other CNS depressant drugs. Patients should also be cautioned not to take alcohol during the administration of lorazepam because of the potentiation of effects that may occur. ATIVAN should not be used during pregnancy. Since lorazepam is also a benzodiazepine derivative, its administration is rarely justified in women of childbearing potential. ATIVAN should not be administered to breast-feeding women, unless the expected benefit to the mother outweighs the potential risk to the infant.

Use of benzodiazepines, including lorazepam, may lead to potentially fatal respiratory depression.

Excessive sedation has been observed with lorazepam at standard therapeutic doses.

The most frequently reported adverse reaction to ATIVAN was drowsiness. See prescribing information for complete adverse reaction information.

The lowest effective dose of ATIVAN should be prescribed for the shortest duration possible. The risk of withdrawal and rebound phenomena is greater after abrupt discontinuation; therefore, the drug should be discontinued gradually. Withdrawal symptoms (e.g., rebound insomnia) can appear following cessation of recommended doses after as little as one week of therapy. Abrupt discontinuation of lorazepam should be avoided and a gradual, dose-tapering schedule followed after extended therapy.

ATIVAN should not be administered to individuals prone to drug abuse. Lorazepam may have abuse potential, especially in patients with a history of drug and/or alcohol abuse.
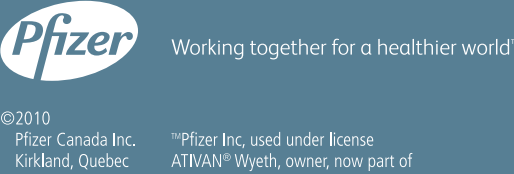